\title{
ARTICLES \\ THE ROLE OF SECTORAL SHIFTS IN THE DECLINE OF REAL GDP VOLATILITY
}

\author{
Daniel Burren and Klaus Neusser \\ University of Bern
}

U.S. production has shifted from goods-producing to service-producing industries. We assess whether this shift contributed to the decline in U.S. output volatility over the period 1949-2005 and provide an estimate of its relative importance. Growth rates of GDP by industry are analyzed in a seemingly unrelated multivariate autoregression framework with time-varying innovation covariance matrices. These changing unobserved covariance matrices are modeled as a Wishart autoregressive process of order one, which results in a nonlinear state-space system. The particle filter is used to obtain estimates of the innovation covariance matrix at each point in time. Several counterfactual experiments make it possible to apportion the decline in output volatility between the shift in the sectoral composition and changes in innovations. Our main finding is that the shift into the service sector can explain about $30 \%$ of the decline in GDP's volatility, despite the fact that some sectors became even more volatile. This result is robust across a wide variety of alternative specifications.

Keywords: Sectoral Shifts, Great Moderation, Stochastic Volatility, Wishart Autoregressive Process, Particle Filter

\section{INTRODUCTION}

The observed decline in U.S. output volatility over the post-WWII period, commonly known as the Great Moderation, triggered a large empirical literature. ${ }^{1}$ Although the decline is well documented and widely accepted, its exact nature still remains controversial. On one hand, Blanchard and Simon (2001) argue for a steady decline over the period 1950 to 2001 . They relate the gradual decay to decline in the volatility of government spending, consumption, and investment and to a change in the sign of the correlation between inventory investment and sales. Furthermore, they find that increased inflation volatility took output volatility temporarily off its declining trend in the 1970s and early 1980s. Blanchard and Simon (2001) state that demand side-shifts have little to do with the general evolution

\footnotetext{
We thank Philippe Bacchetta, Gregor Bäurle, Bo E. Honoré, Stefan Leist, Lukas Schmid, Martin Wagner and seminar participants at the University of Bern and the Study Center Gerzensee for useful comments. We also acknowledge the constructive criticism of the referee and the suggestions by the editor. All remaining errors are of course ours. Address correspondence to: Klaus Neusser, Department of Economics, University of Bern, Schanzeneckstrasse 1, P.O. Box 8573, CH-3001 Berne, Switzerland; e-mail: klaus.neusser@ vwi.unibe.ch.
} 
of output volatility. On the other hand, Stock and Watson (2005b) and Fang and Miller (2008) present evidence for a sharp break around 1984. They attribute this to a combination of improved policy (20 to $30 \%$ ), good luck in the form of reduced commodity price shocks (20 to $30 \%$ ), and further nonidentifiable elements. More recently, Galí and Gambetti (2009) have presented a more complex picture that goes beyond the pure good luck hypothesis. They point to some deeper underlying structural changes in the U.S. economy.

This paper focuses on the structural changes in the sectoral composition of the U.S. economy and establishes the contribution of these changes to the explanation of the Great Moderation. Not only do we present a more detailed characterization of the volatility decline in terms of timing, but we also propose a new device for modeling time-varying variance-covariance matrices.

More specifically, we investigate the evolution of U.S. NAICS GDP by industry data in two stages. In a first stage, we estimate an autoregression of order one, $\operatorname{AR}(1)$, for each sectoral growth-rate series. We check the stability of the regression parameters and the innovation variances against the alternative of an unknown break date. Interestingly, we find that the innovation variance increased for the mining, utilities, and information sectors, but decreased only for the durable goods sector. This goes against the Good Luck hypothesis, which attributes the Great Moderation to a decline in the magnitude of shocks [see Stock and Watson (2005b)]. We then use the estimated AR(1) processes to run counterfactual Monte Carlo experiments. Drawing the innovation errors from a multivariate normal distribution with covariance matrix corresponding to the pre-1984 (post-1984) period, we establish that sectoral shifts explain approximately $30 \%(15 \%)$ of the decline in output volatility.

In the second stage, we allow the covariance matrix of the innovations to change smoothly over time. More precisely, we assume that the covariance matrix of the innovations follows a Wishart autoregressive process of order one (WAR(1)). This process has been introduced by Gourieroux et al. (2009) to model multivariate stochastic volatility. It has the property that it naturally accommodates the positiveness and symmetry of covariance matrices. ${ }^{2}$ Although these features are also shared by other approaches [see for example Primiceri (2005)], the WAR representation has the advantage that it can capture a wide range of smooth evolutions in a parsimonious way. Moreover, it makes it possible to write the multivariate process of sectoral growth rates as a nonlinear state-space system, with the covariance matrix being the unobserved state. The nonlinearity of the system precludes the use of the Kalman filter to infer the unobserved state. The particle filter, however, still provides a valid alternative procedure that makes it possible to estimate the unobserved covariance matrices. These estimates can then be used to run further counterfactual exercises. Again we find that structural shifts, particularly in favor of the service sector, can account for more than one-fifth of the Great Moderation.

The paper is structured as follows. Section 2 presents the dataset and some preliminary findings. These results allows a first corroboration of our hypothesis. Section 3 reviews the Wishart process and the particle filter, together with the 
implementation of the estimation procedure. Section 4 presents the empirical results. Section 5 concludes the paper.

\section{DATA AND PRELIMINARY RESULTS}

\subsection{Data Description}

We use two-digit annual U.S. GDP by industry series from the Gross-DomesticProduct-by-Industry Accounts (Bureau of Economic Analysis) ranging from 1948 to 2005. These series sum up to nominal GDP. They were deflated using the implicit GDP deflator ${ }^{3}$ and expressed in per capita terms using the civilian noninstitutional population index from the Bureau of Labor Statistics. The dataset consists of 22 sectors, listed in Table 1. Except when noted otherwise, growth rates are computed in the usual way as

$$
100 \frac{X_{t}-X_{t-1}}{X_{t-1}}
$$

As a first check of our hypothesis, we plot the average sectoral growth rates against their coefficient of variation. ${ }^{4}$ The corresponding Figure 1 clearly reveals a negative relationship with a correlation coefficient of -0.47 . Thus, less volatile sectors have grown faster than more volatile ones. This implies that the growing share of low-volatility sectors led to a decline in aggregate volatility, i.e., the volatility of GDP growth. The aim of our paper is to quantify this effect and check how much it contributes to the Great Moderation.

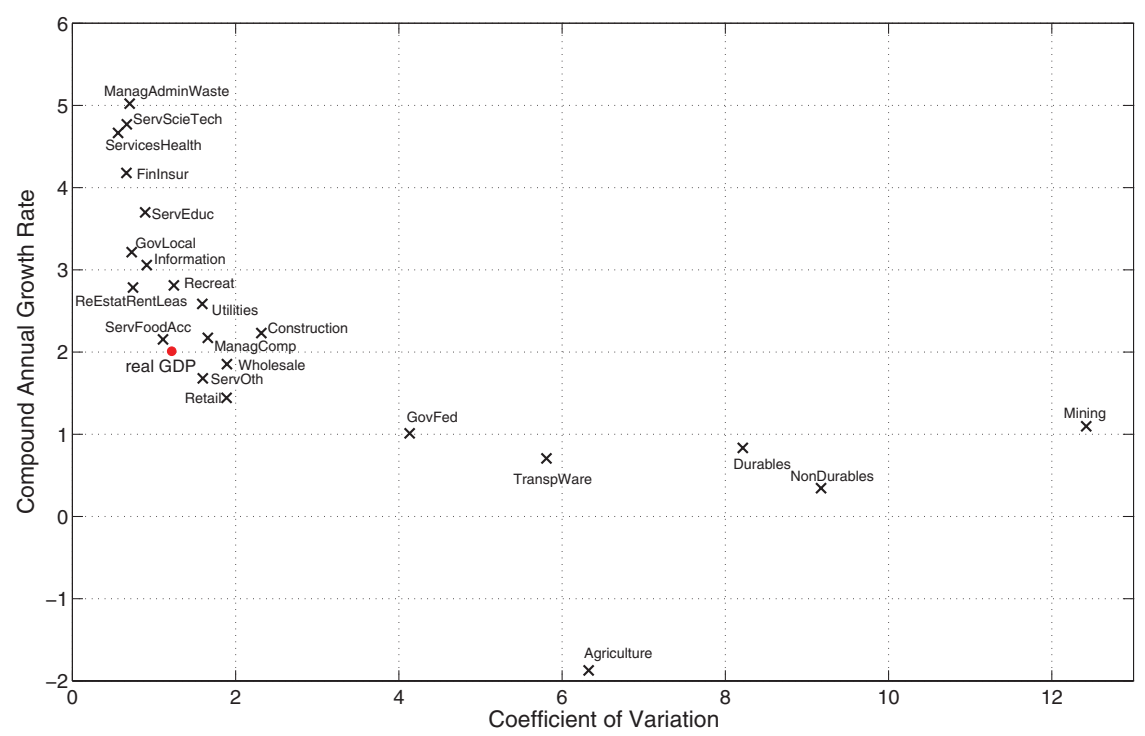

FIGURE 1. Growth and coefficient of variation. 
TABLE 1. Sectors with some summary statistics

\begin{tabular}{|c|c|c|c|c|c|}
\hline \multirow[b]{2}{*}{ Sector } & \multirow[b]{2}{*}{ Abbreviation } & \multicolumn{2}{|c|}{ Share in } & \multirow{2}{*}{$\begin{array}{l}\text { Compound } \\
\text { annual } \\
\text { growth rates }\end{array}$} & \multirow{2}{*}{$\begin{array}{l}\text { Std of } \\
\text { growth } \\
\text { rate }\end{array}$} \\
\hline & & 1950 & 2005 & & \\
\hline $\begin{array}{l}\text { Agriculture-forestry- } \\
\text { fishing-hunting }\end{array}$ & Agriculture & 6.8 & 0.9 & -1.87 & 11.85 \\
\hline Mining & Mining & 2.6 & 1.7 & 1.10 & 13.63 \\
\hline Utilities & Utilities & 1.6 & 1.9 & 2.58 & 4.12 \\
\hline Construction & Construction & 4.4 & 4.8 & 2.23 & 5.16 \\
\hline Durable goods & Durables & 14.8 & 7.0 & 0.83 & 6.85 \\
\hline Nondurable goods & NonDurables & 12.2 & 5.0 & 0.34 & 3.15 \\
\hline Wholesale trade & Wholesale & 6.3 & 5.9 & 1.85 & 3.51 \\
\hline Retail trade & Retail & 8.8 & 6.6 & 1.44 & 2.73 \\
\hline $\begin{array}{l}\text { Transportation and } \\
\text { warehousing }\end{array}$ & TranspWare & 5.9 & 2.9 & 0.71 & 4.10 \\
\hline Information & Information & 2.3 & 4.6 & 3.06 & 2.78 \\
\hline Finance and insurance & FinInsur & 2.7 & 8.1 & 4.18 & 2.77 \\
\hline $\begin{array}{l}\text { Real estate-rental } \\
\text { and leasing }\end{array}$ & ReEstatRent & 8.7 & 12.5 & 2.78 & 2.07 \\
\hline $\begin{array}{l}\text { Professional—scientific } \\
\text { and technical services }\end{array}$ & ServScieTech & 1.6 & 6.9 & 4.77 & 3.18 \\
\hline $\begin{array}{l}\text { Management of companies } \\
\text { and enterprises }\end{array}$ & ManagComp & 1.7 & 1.8 & 2.17 & 3.61 \\
\hline $\begin{array}{l}\text { Administrative and waste } \\
\text { management services }\end{array}$ & ManagAdminWaste & 0.6 & 3.0 & 5.02 & 3.53 \\
\hline Education services & ServEduc & 0.4 & 0.9 & 3.70 & 3.30 \\
\hline $\begin{array}{l}\text { Health care and social } \\
\text { assistance }\end{array}$ & ServicesHealth & 1.7 & 6.9 & 4.67 & 2.61 \\
\hline $\begin{array}{l}\text { Arts-entertainment } \\
\text { and recreation }\end{array}$ & Recreat & 0.6 & 0.9 & 2.81 & 3.49 \\
\hline $\begin{array}{l}\text { Accommodation and } \\
\text { food services }\end{array}$ & ServFoodAcc & 2.4 & 2.7 & 2.15 & 2.39 \\
\hline $\begin{array}{l}\text { Other services without } \\
\text { government }\end{array}$ & ServOth & 2.8 & 2.4 & 1.68 & 2.68 \\
\hline Federal government & GovFed & 6.2 & 4.0 & 1.01 & 4.18 \\
\hline State and local government & GovLocal & 4.6 & 8.5 & 3.21 & 2.33 \\
\hline Real GDP per capita & & & & 2.01 & 2.45 \\
\hline
\end{tabular}

Note: Sample period: $1949-2005$.

\subsection{Univariate Analysis of Sectoral Growth Rates}

Before proceeding to the multivariate analysis that is the focus of our investigation, we exploit the univariate time series properties of sectoral growth rates. This serves two purposes: First, we want to prepare the ground by common and 
comprehensible techniques and persuade the reader that there is indeed a scope for deeper investigation; second, the process provides some indication of the appropriate multivariate specification.

We model each sectoral growth rate as a simple autoregressive processes of order one (AR(1) process), but allow structural breaks in the coefficients at some unknown date:

$$
\begin{aligned}
x_{t}^{i}= & {\left[1-d_{t}(\tau)\right] c_{1}^{i}+d_{t}(\tau) c_{2}^{i}+\left[\left(1-d(\tau)_{t}\right) \phi_{1}^{i} x_{t-1}^{i}+d_{t}(\tau) \phi_{1}^{i} x_{t-1}^{i}+\varepsilon_{t}^{i},\right.} \\
\varepsilon_{t}^{i} & \left.\sim \operatorname{MDS}\left(0, \sigma^{2}\left(\varepsilon_{t}^{i}\right)\right)\right],
\end{aligned}
$$

where $x_{t}^{i}$ denotes the growth rate of sector $i . d_{t}(\tau)$ is a dummy variable variable that takes the value zero for $t<\tau$ and one for $t \geq \tau$. $\tau$ denotes the (unknown) date of the break point. The innovations $\varepsilon_{t}^{i}$ are assumed to be martingale differences sequences (MDS) with possibly time-varying variances $\sigma^{2}\left(\varepsilon_{t}^{i}\right)$. The dummy variable effectively breaks the sample into two parts. A simple AR(1) model with constants $c_{1}^{i}$ and autoregressive coefficients $\phi_{1}^{i}$, respectively $c_{2}^{i}$ and $\phi_{2}^{i}$, is estimated for each subsample. ${ }^{5}$

Testing structural breaks in mean. We assess the null hypothesis of constant parameters against the alternative of a single unknown break time by the AndrewsPloberger test [see Andrews and Ploberger (1994)]. The corresponding test statistic is given by

$$
\xi_{W}=\sup _{\lfloor 0.15 T\rfloor \leq \tau \leq T-\lfloor 0.15 T\rfloor} W(\tau)
$$

where $W(\tau)$ denotes the Wald test statistic for the joint null hypothesis $c_{1}=c_{2}$ and $\phi_{1}=\phi_{2}$ given a break point at date $\tau$. The appropriate test statistics is then obtained by taking the supremum over all $W(\tau)$, where $\tau$ varies in a given time interval. The time interval is set $[\lfloor 0.15 T\rfloor,\lfloor T-0.15 T\rfloor]$, where $T$ denotes the sample size and 0.15 is the recommended trimming factor. The critical values are provided by Andrews and Ploberger (1994). Note that they remain valid even for heteroskedastic residuals as long as a robust estimator is used for the covariance matrix in the Wald statistic. The value $\tau^{*}=\arg \max W(\tau)$ provides an estimate of the break period.

The evidence presented in Table 2 shows significant breaks (at the 5\% level) for mining, utilities, retail trade, real estate-rental and leasing, professionalscientific and technical services, education services, health care and social assistance, accommodation and food services, and state and local government, but none for agriculture and federal government. The $F$-statistics indicates that an AR(1) model with possibly changing coefficients is sufficient to characterize the sectoral growth rates. We have omitted the results for the agricultural and federal government sector in Table 2 because they fall outside the AR(1) framework of equation (1). 
TABLE 2. Andrews-Ploberger parameter stability test

\begin{tabular}{lccccccccc}
\hline Sector & $\hat{c}_{1}^{i}$ & $\hat{c}_{2}^{i}$ & $\hat{\phi}_{1}^{i}$ & $\hat{\phi}_{2}^{i}$ & $\hat{\mu}_{1}$ & $\hat{\mu}_{2}$ & $\max W$ & $F$-stat & $\tau^{*}$ \\
\hline Mining & 2.18 & 1.02 & 0.30 & 0.13 & 3.11 & 1.17 & 10.11 & 2.29 & 1956 \\
& $(1.81)$ & $(3.35)$ & $(0.17)$ & $(0.16)$ & $(5.69)$ & $(3.96)$ & & & \\
Utilities & 3.73 & 1.71 & 0.33 & 0.09 & 5.58 & 1.88 & 17.74 & 0.32 & 1987 \\
& $(2.15)$ & $(0.79)$ & $(0.20)$ & $(0.20)$ & $(10.39)$ & $(1.17)$ & & & \\
Retail & 1.35 & 0.81 & 0.15 & 0.35 & 1.60 & 1.25 & 13.23 & 0.06 & 1960 \\
& $(0.64)$ & $(0.56)$ & $(0.17)$ & $(0.27)$ & $(0.83)$ & $(0.50)$ & & & \\
ReEstatRentLeas & 1.24 & 2.93 & 0.56 & -0.31 & 2.79 & 2.23 & 20.46 & 0.21 & 1986 \\
& $(0.47)$ & $(0.91)$ & $(0.12)$ & $(0.31)$ & $(0.82)$ & $(1.54)$ & & & \\
ServScieTech & 8.18 & 2.95 & -0.21 & 0.35 & 6.75 & 4.55 & 24.95 & 0.36 & 1967 \\
& $(1.60)$ & $(0.76)$ & $(0.23)$ & $(0.13)$ & $(9.57)$ & $(2.78)$ & & & \\
ServEduc & 1.18 & 3.01 & 0.67 & 0.21 & 3.54 & 3.79 & 20.58 & 0.22 & 1977 \\
ServHealth & $(0.59)$ & $(1.21)$ & $(0.10)$ & $(0.25)$ & $(1.46)$ & $(3.51)$ & & & \\
& 9.21 & 2.25 & -0.55 & 0.43 & 5.96 & 3.97 & 26.35 & 0.17 & 1992 \\
ServFoodAcc & $(1.64)$ & $(0.65)$ & $(0.22)$ & $(0.16)$ & $(8.96)$ & $(1.67)$ & & & \\
& 2.25 & 1.83 & -0.73 & 0.26 & 1.30 & 2.46 & 22.43 & 0.01 & 1962 \\
GovLocal & $(0.60)$ & $(0.38)$ & $(0.23)$ & $(0.07)$ & $(0.68)$ & $(0.87)$ & & & \\
& 0.73 & 1.02 & 0.77 & 0.36 & 3.23 & 1.60 & 64.42 & 1.01 & 1956 \\
& $(0.39)$ & $(0.46)$ & $(0.09)$ & $(0.24)$ & $(0.75)$ & $(0.28)$ & & & \\
\hline
\end{tabular}

Note: White's robust standard deviations are in parentheses. $\max W$ is the maximum Wald statistic from the Andrews test; the $5 \%$ critical value is 8.68 . The $F$-stat tests the significance of remaining autocorrelation in residuals up to lag two; its theoretical 95th quantile is 3.18. $\tau^{*}$ is an estimate of the break period. The estimated mean growth rate for sector $i$ is $\hat{\mu}^{i}=c^{i} / 1-\phi^{i}$ and its standard deviation is obtained using the delta method.

Testing structural breaks in variance. We next examine the evolution of innovation variances. According to the Good Luck hypothesis, economic fluctuations have moderated because of less volatile shocks. If this is true, we should see a decline in the innovation variances of sectoral growth rates; i.e., the variances of the $\varepsilon_{t}^{i}$ should have decreased. We investigate this hypothesis using a test proposed by Inclán and Tiao (1994) that is based on an iterated cumulative sums of squares (ICSS) algorithm. We apply the test to the residuals from the AR(1) regressions (see equation (1)). We replace model (1) with a simple AR(1) model if the Andrews-Ploberger test does not detect a break in the parameters.

The evidence reported in Table 3 shows significant one-time breaks in the variances of mining, utilities, durable goods, and information with break dates

TABLE 3. Variance break test

\begin{tabular}{lcrrrr}
\hline Sector & Break date $\tau$ & $\sigma\left(\varepsilon_{t<\tau}^{i}\right)$ & $\sigma\left(\varepsilon_{t \geq \tau}^{i}\right)$ & $\sigma\left(x_{t<\tau}^{i}\right)$ & $\sigma\left(x_{t \geq \tau}^{i}\right)$ \\
\hline Mining & 1973 & 5.66 & 16.47 & 5.92 & 16.84 \\
Utilities & 1973 & 2.10 & 4.19 & 3.46 & 4.14 \\
Durables & 1959 & 11.22 & 5.74 & 9.50 & 6.02 \\
Information & 1995 & 2.30 & 4.32 & 2.36 & 4.15 \\
\hline
\end{tabular}


1973, 1973, 1959, and 1995, respectively. ${ }^{6}$ Table 3 also reports the estimated conditional and unconditional standard deviations before and after the break date.

Note that the innovation variances of mining, utilities, and information actually increased, which goes against the wisdom that GDP growth has become more stable thanks to less volatile economic shocks. In addition, there seems to be no relation between parameter breaks and conditional variance breaks. Only for mining and utilities there is evidence for breaks in both parameters and innovation variance. The break dates, however, lie several years apart.

Inclán and Tiao (1994) point out that their test has low power in samples with less than 100 observations if the change in variance is small. Therefore, we take 1984 as the potential break date. This corresponds to the break date indicated by the ICSS test for GDP growth and is also proposed by Stock and Watson (2005b). If the Good Luck hypothesis is true, the innovation variances of the sectoral growth rates should have dropped at the same time as the variance of GDP growth. As the break date is known, we can use the Goldfeld-Quandt test. The test statistic is given by

$$
F=\frac{\hat{\sigma}^{2}\left(\varepsilon_{t<1984}^{i}\right)}{\hat{\sigma}^{2}\left(\varepsilon_{t \geq 1984}^{i}\right)} \sim F_{n_{1}-K, n_{2}-K}
$$

where $\varepsilon_{t}^{i}$ denotes the corresponding residuals. Under the null of equal variances the test statistic has a $F$-distribution with $n_{1}-K$ and $n_{2}-K$ degrees of freedom ( $n_{i}$ being the number of observations in subsample $i$ and $K$ being the number of regressors). Because the alternative hypothesis is a decrease in sectoral innovation variances, the $5 \%$ critical value is given by the 0.95 quantile, which is 2.04 in the present case.

The results in Table 4 indicate that only the variances for durable goods, nondurable goods, retail trade, transportation and warehousing, and state and local government decreased significantly, not the variances for the remaining sixteen sectors. $^{7}$ This evidence therefore does not support the Good Luck hypothesis. However, we conclude that changes in the innovation variances indeed took place.

Sectoral shifts and output volatility. We end this preliminary investigation by providing some first evidence of the role of sectoral shifts in output volatility. Denote by $\varsigma_{t}$ the vector of sectoral shares, defined as the ratio of sectoral real value added over total real GDP, and by $\widehat{W}$ the sample covariance matrix of the residual vector $\hat{\varepsilon}_{t}=\left(\hat{\varepsilon}_{t}^{1}, \ldots, \hat{\varepsilon}_{t}^{22}\right)^{\prime}$. Then $\zeta_{t}^{\prime} \widehat{W} \varsigma_{t}$ can be considered as an estimate of real GDP volatility taking the change in the sectoral composition into account. This entity declined steadily from almost 2.9 in the 1950 s to 2.1 in 2005, as shown in Figure 2. This finding corroborates our hypothesis. The analysis is, however, incomplete because the covariance matrix $W$ is not constant over time. We account for this fact in the following sections. 
TABLE 4. Standard deviations and Goldfeld-Quandt structural break test with fixed break date 1984

\begin{tabular}{lccccc}
\hline Sector & $\sigma\left(\varepsilon_{t<1984}^{i}\right)$ & $\sigma\left(\varepsilon_{t \geq 1984}^{i}\right)$ & $\sigma\left(x_{t<1984}^{i}\right)$ & $\sigma\left(x_{t \geq 1984}^{i}\right)$ & F-stat \\
\hline Agriculture & 11.42 & 11.21 & 11.09 & 13.12 & 1.04 \\
Mining & 11.31 & 16.03 & 11.61 & 16.25 & 0.50 \\
Utilities & 3.71 & 2.91 & 4.36 & 3.11 & 1.63 \\
Construction & 5.09 & 4.27 & 5.37 & 4.87 & 1.42 \\
Durables & 8.03 & 4.67 & 8.04 & 4.61 & $2.95^{*}$ \\
Nondurables & 3.62 & 2.17 & 3.66 & 2.27 & $2.79^{*}$ \\
Wholesale & 3.81 & 2.94 & 3.92 & 2.87 & 1.68 \\
Retail & 3.12 & 1.90 & 2.85 & 2.54 & $2.70^{*}$ \\
TranspWare & 4.72 & 2.84 & 4.68 & 2.92 & $2.76^{*}$ \\
Information & 2.36 & 3.34 & 2.33 & 3.41 & 0.50 \\
FinInsur & 2.56 & 2.35 & 3.02 & 2.40 & 1.18 \\
ReEstRentLeas & 1.83 & 1.63 & 2.26 & 1.77 & 1.60 \\
ServScieTech & 2.81 & 3.15 & 2.82 & 3.71 & 0.80 \\
ManagComp & 3.72 & 3.51 & 3.64 & 3.55 & 1.12 \\
ManagAdminWaste & 3.12 & 3.77 & 3.06 & 4.18 & 0.69 \\
ServEduc & 2.80 & 2.01 & 4.00 & 1.95 & 1.96 \\
ServHealth & 2.17 & 2.10 & 2.62 & 2.36 & 1.06 \\
Recreat & 3.06 & 3.99 & 3.00 & 3.90 & 0.59 \\
ServFoodAcc & 2.40 & 1.89 & 2.59 & 2.05 & 1.61 \\
ServOth & 2.87 & 2.17 & 2.73 & 2.45 & 1.74 \\
GovFed & 4.85 & 2.19 & 5.06 & 2.35 & $4.89^{*}$ \\
GovLocal & 1.44 & 0.80 & 2.65 & 1.08 & $3.26^{*}$ \\
\hline
\end{tabular}

Note: The theoretical 95th quantile of the $F$-distribution for testing the equality of the variance of $\varepsilon_{t}^{i}$ is 2.04 .

\section{SMOOTHLY CHANGING COVARIANCE MATRIX}

In contrast to Stock and Watson (2005a) and Fang and Miller (2008), Blanchard and Simon (2001) argued that U.S. output volatility did not drop suddenly around 1984, but declined steadily over time. As a consequence, the covariance matrix of the AR(1) innovations should have changed steadily too. We investigate this hypothesis by modeling the covariance matrix as a latent variable with an autoregressive structure of order one. In order to respect the character of a covariance matrix, we follow Gourieroux et al. (2009) and model the covariance matrix as a Wishart autoregressive process of order one (WAR(1)).

\subsection{The Wishart Autoregressive Process}

The sectoral growth rates $x_{t}=\left(x_{t}^{1}, \ldots, x_{t}^{22}\right)^{\prime}$ are assumed to follow an $\operatorname{AR}(1)$ process as described. However, we allow the covariance matrix of the innovations, 


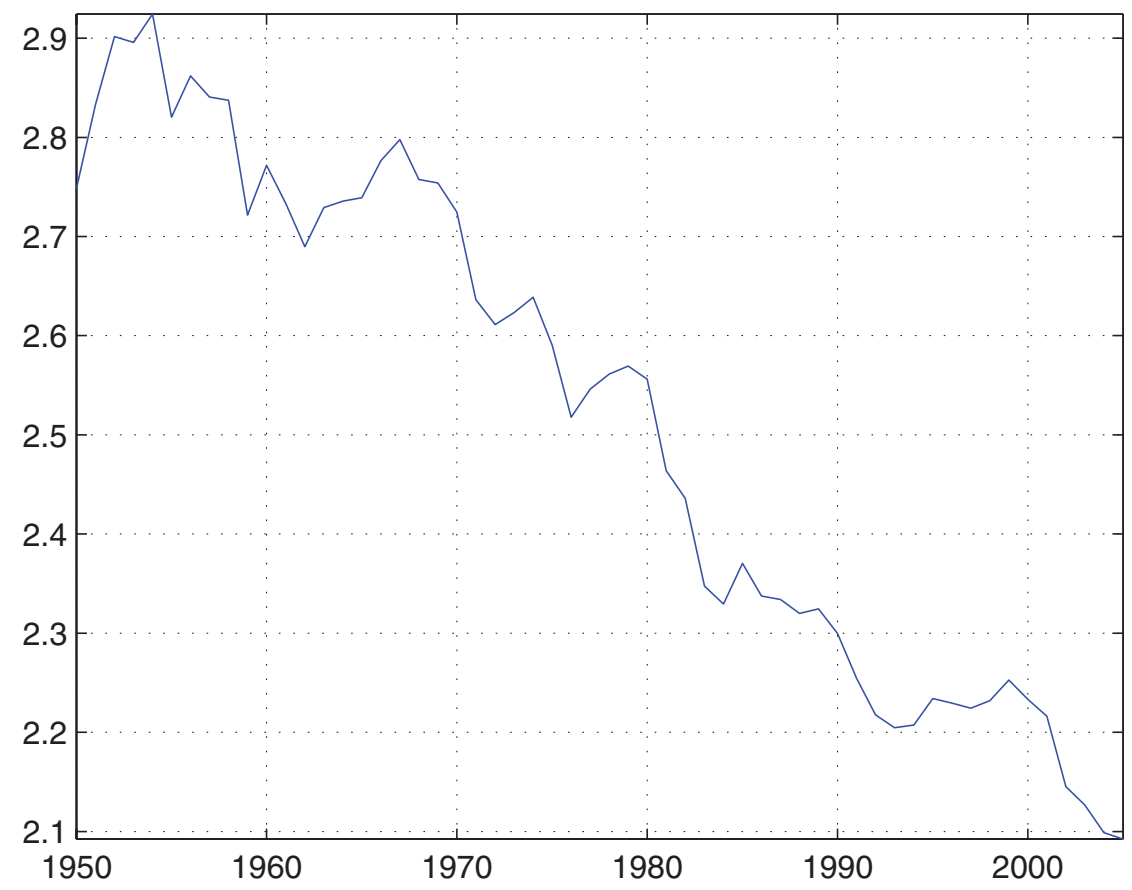

FIGURE 2. Volatility of GDP as implied by sectoral volatility $\left(\sqrt{\varsigma_{t}^{\prime} \widehat{W} \varsigma_{t}}\right)$.

$W_{t}$, to be time-dependent. In particular, we adopt the state-space system

$$
\begin{aligned}
x_{t} \mid W_{t} & \sim \mathrm{N}\left(c_{t}+\Phi_{t} x_{t-1}, W_{t}\right), \\
W_{t} \mid W_{t-1} & \sim \operatorname{WAR}(1),
\end{aligned}
$$

where (2) is the observation equation and (3) the transition equation for the covariance matrix $W_{t}$. The vector of constants is denoted by $c_{t}$ and $\Phi_{t}$ is the diagonal matrix with elements $\phi_{t}^{i}$. Sectoral interactions through autoregressive components are excluded, based on the empirical findings of Neusser (2008). The coefficients are indexed by time to allow for the breaks detected in Section 2.2.

Following the seminal contribution of Gourieroux et al. (2009), we model the covariance matrices $\left(W_{t}\right)$ as a Wishart process of order one (WAR(1) process). The WAR(1) process is an autoregressive process for covariance matrices with given dimension $n_{s}$. Its moment-generating function, $\mathcal{M}(\Gamma)$, is

$$
\mathcal{M}(\Gamma)=\mathbf{E}_{t}\left[\exp \left(\operatorname{Tr}\left(\Gamma W_{t+1}\right)\right)\right]=\frac{\exp \left(\operatorname{Tr}\left[M^{\prime} \Gamma\left(\mathrm{I}_{n_{s}}-2 \Sigma \Gamma\right)^{-1} M W_{t}\right]\right)}{\left[\operatorname{det}\left(\mathrm{I}_{n_{s}}-2 \Sigma \Gamma\right)\right]^{K / 2}},
$$

where $\mathbf{E}_{t}$ is the expectation operator conditional on information up to time $t$ and $\mathrm{Tr}$ 
the trace operator. The $n_{s} \times n_{s}$ matrix $M$ comprises the autoregressive parameters of the process, and $\Sigma$ is on $n_{s} \times n_{s}$ symmetric and positive definite matrix. The degree of freedom $K$ is a positive number satisfying $K>n_{s}-1$. $\mathrm{I}_{n_{s}}$ is the identity matrix of dimension $n_{s}$. The moment-generating function is defined for symmetric matrices $\Gamma$ with $\|2 \Sigma \Gamma\|<1 .^{8}$

Assuming that the degree of freedom $K$ is an integer, the process can be rewritten in an instructive way as

$$
W_{t}=\sum_{k=1}^{K} z_{k, t} z_{k, t}^{\prime}
$$

where $\left(z_{k t}\right), k=1, \ldots, K$, are independent Gaussian vector processes of dimension $n_{s}$ that satisfy

$$
z_{k, t}=M z_{k, t-1}+e_{k, t}, \quad e_{k, t} \sim \operatorname{IIDN}(0, \Sigma) .
$$

If $K=1, M=0$, and $\Sigma=1$, one can recognize the $\chi^{2}(1)$ distribution as a special case of the Wishart distribution. Observe that the stochastic matrix $W_{t}$ is of full rank with probability one if the degree of freedom, denoted by $K$, is equal to or greater than $n_{s}$.

It is instructive to analyze the behavior of $\left(W_{t}\right)$ as the degree of freedom, $K$, goes to infinity. Obviously, if the covariance matrix $\Sigma$ of the $e_{k, t}$ vectors is independent of $K,\left(W_{t}\right)$ has an exploding second moment matrix as $K \rightarrow \infty$. However, we can consider the transformed processes $\tilde{z}_{k, t}:=\sqrt{K} z_{k, t}$ and $\Sigma(K)=K^{-1} \tilde{\Sigma}$, where $\tilde{\Sigma}$ is a constant matrix, and write

$$
W_{t}=\frac{1}{K} \sum_{k=1}^{K} \tilde{z}_{k, t} \tilde{z}_{k, t}^{\prime}
$$

where

$$
\tilde{z}_{k, t}=M \tilde{z}_{k, t-1}+\tilde{e}_{k, t}, \quad \tilde{e}_{k, t} \sim \operatorname{IIDN}(0, \tilde{\Sigma})
$$

If all eigenvalues of $M$ are strictly inside the unit circle, the unconditional distribution of $\tilde{z}_{k, t}$ is $\mathrm{N}(0, \tilde{\Sigma}(\infty))$, where $\tilde{\Sigma}(\infty)$ solves

$$
\tilde{\Sigma}(\infty)=M \tilde{\Sigma}(\infty) M^{\prime}+\tilde{\Sigma}
$$

Given a sample $\left\{\tilde{z}_{k, t} \tilde{z}_{k, t}^{\prime}\right\}_{k=1}^{K}$ of identically and independently distributed random variables with finite second-order moments, the strong law of large numbers implies that the sum in equation (4) converges almost surely to $\mathbf{E}\left[\tilde{z}_{k, t} \tilde{z}_{k, t}^{\prime}\right]$ as $K \rightarrow \infty$. Therefore, in the limit as $K \rightarrow \infty$, the WAR(1) process is a degenerated process with constant matrices as its realizations. We will use this fact to calibrate the process (Section 3.3). 
Note that the Wishart specification is conceptually quite different from the class of multivariate generalized ARCH (MGARCH) models: ${ }^{9}$

(i) In a MGARCH model, the volatility of $x_{t+1}$ conditional on information up to time $t$ depends on past realizations of growth rates. This is not the case for the state-space system with the Wishart specification.

(ii) The estimation of volatility matrices in a MGARCH framework requires estimating a large number of parameters. Even the multivariate ARCH(1) model, given by

$$
\operatorname{vech}\left(\Sigma_{t}\right)=b+A \operatorname{vech}\left(\left(x_{t}-c_{t}-\Phi_{t} x_{t-1}\right)\left(x_{t}-c_{t}-\Phi_{t} x_{t-1}\right)^{\prime}\right)
$$

involves

$$
\left(\frac{n_{s}\left(n_{s}+1\right)}{2}\right)^{2}+\frac{n_{s}\left(n_{s}+1\right)}{2}
$$

parameters. ${ }^{10}$ The literature has proposed to put restrictions on the parameters [see, for example, Engle and Kroner (1993)], which, however, can be "complicated and hard to interpret" 11 because they have to be such that the conditional volatility matrices are positive definite, whereas the WAR(1) model requires only

$$
n_{s}^{2}+\frac{n_{s}\left(n_{s}+1\right)}{2}+1
$$

parameters.

\subsection{Particle Filter}

The observation equation (2) and the transition equation (3) form a state-space system. Because of its nonlinearity, the Kalman filter cannot be applied. Therefore the particle filter (sequential Monte Carlo filter) is used to draw from the posterior distribution of the covariances $W_{t}$ given the observed growth rates up to time $t$. For a detailed discussion on particle filtering methods, we refer to Arulampalam et al. (2002). ${ }^{12}$ The parameters of the model, $M, \Sigma$, and $K$, are subsumed into $\theta$ and the density of $W_{t}$ given the observed growth rates up to date $t$ is denoted by $p\left(W_{t} \mid x_{1: t}, \theta\right) . f_{x}\left(x_{t} \mid W_{t}\right)$ refers to the density of $x_{t}$ given $W_{t}$, and $f_{w}\left(W_{t} \mid W_{t-1}, \theta\right)$ to the transition density of the WAR(1). Given this notation, the particle filter consists of the following three steps:

Step 1. Initialization. Draw $N$ times from the unconditional distribution of $W_{0}$, denoted by $p\left(W_{0} \mid \theta\right)$. This gives a sample of $N$ particles, which is denoted by $\left\{w_{0 \mid 0}^{i}\right\}_{i=1}^{N}$.

Step 2. Prediction. For each of the particles in the sample from the previous step, given by $\left\{w_{t-1, t-1}^{i}\right\}_{i=1}^{N}$, generate one draw from $f_{w}\left(W_{t} \mid w_{t-1, t-1}^{i}, \theta\right)$. The result is a sample of $N$ particles, $\left\{w_{t \mid t-1}^{i}\right\}_{i=1}^{N}$, that are drawn from $p\left(W_{t} \mid x_{1: t-1}, \theta\right)$. 
Step 3. Updating. Draw, with replacement, $N$ times from the previous sample, $\left\{w_{t \mid t-1}^{i}\right\}_{i=1}^{N}$. The probability of drawing $w_{t \mid t-1}^{i}$ is given by the so-called normalized importance weight, denoted by $\pi_{t}^{i}$, which is calculated according to

$$
\pi_{t}^{i}=\frac{f_{x}\left(x_{t} \mid w_{t \mid t-1}^{i}\right)}{\sum_{i=1}^{N} f_{x}\left(x_{t} \mid w_{t \mid t-1}^{i}\right)} .
$$

The resulting sample is a draw from the discretized density $p\left(W_{t} \mid x_{1: t}, \theta\right)$.

\subsection{Implementation}

We implement the Wishart model based on the following assumptions. First, the autoregressive matrix $M$ is restricted to $M=\sqrt{\lambda} \mathrm{I}_{n_{s}}$, with $\lambda$ equal to $0.8{ }^{13}$ The exclusion of interactions among sectors through the autoregressive matrix $M$ can be justified by the evidence presented in Neusser (2008), although the context and the data are not comparable. He does not find a sensible and significant intersectoral covariance structure of innovations in his analysis of sectoral total factor productivity (TFP) growth. Second, we set $K$ equal to the number of sectors, i.e., 19. ${ }^{14}$ This choice is motivated by the fact that a value for $K$ less than 19 would lead to singular covariance matrices and that values greater than 19 would result in more persistent covariance matrices, which in turn would magnify the role played by sectoral shifts. Third, we determine $\Sigma$ by setting $K \Sigma$ equal to the sample covariance matrix of the data multiplied by $(1-\lambda)$. This calibration is justified by the convergence of $W_{t}$ to $\tilde{\Sigma}(\infty)$. If $\tilde{\Sigma}(\infty)$ is assumed to be close to the sample covariance matrix, equation (5) implies that $K \Sigma=\tilde{\Sigma}=(1-\lambda)$ $\tilde{\Sigma}(\infty)$.

The particle filter is run 20 times, drawing 20,000 particles each time. Then we average the 20 estimates of $\mathbf{E}\left[W_{t} \mid x_{1: t}\right]$ and take this as an estimator for the standard deviation. We initialize the filter by setting $z_{k, 0}=x_{k}-c_{k}-\Phi_{k} x_{k-1}$, where $k$ runs over the first nine years of our sample.

Although it is known that the particle filter can suffer from a degeneracy problem, i.e., that after a few iterations, only one particle gets through the filter, we did not encounter this problem. As an illustration, Figure A.1 in Appendix A shows the 2005-posterior distributions of all covariance matrix elements associated with durable goods production.

\section{RESULTS}

Comparing the results of the ICSS variance break tests in Table 3 with Figures 8.18.4 in Appendix B shows that the filtered standard deviations of mining, utilities, durable goods, and information square well with the findings of the ICSS variance break test. ${ }^{15}$ This indicates that the evidence produced by the WAR model is sensible. 


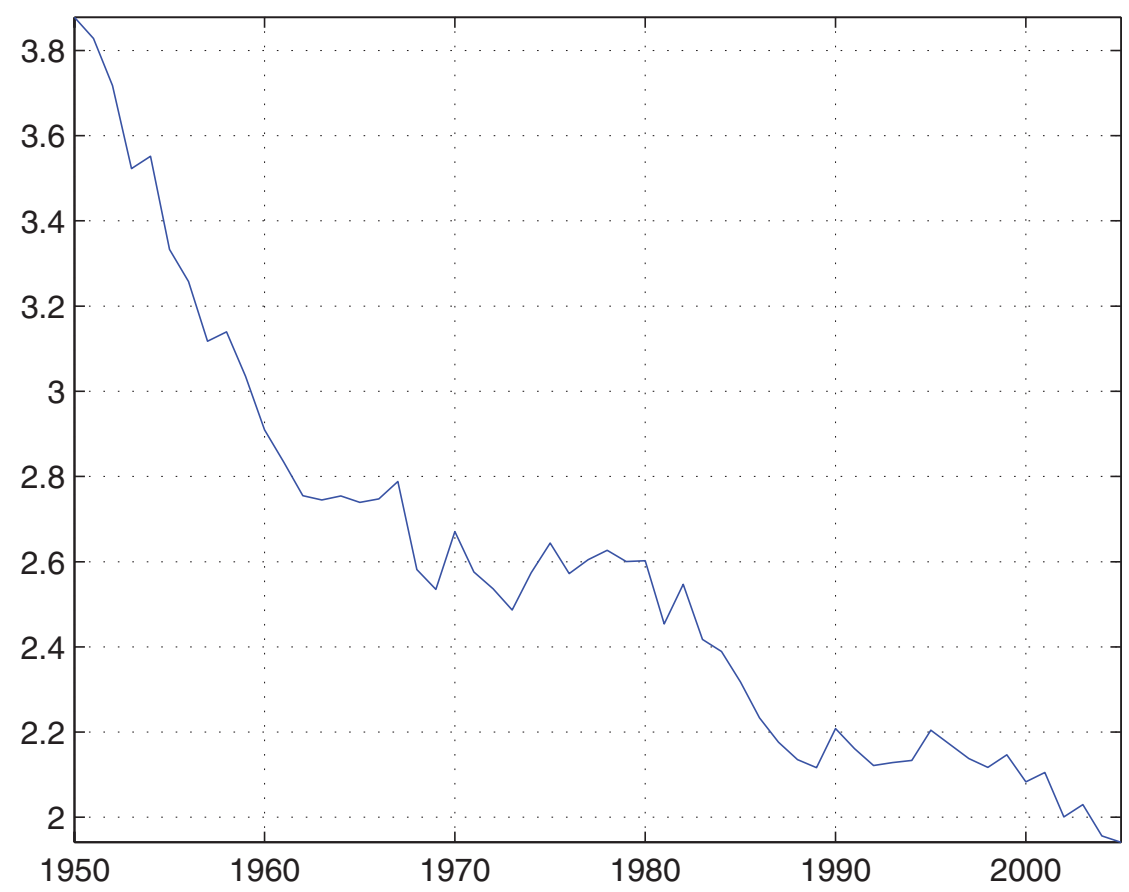

FIGURE 3. Conditional standard deviation of GDP.

\subsection{Conditional GDP Volatility}

We use the filtered covariance matrices to assess the dependence of the conditional standard deviation of GDP growth on sectoral shares. The variance of real GDP growth rates $\Delta y_{t} / y_{t-1}$ is formally given as

$$
\mathbf{V}_{t-1}\left(\frac{\Delta y_{t}}{y_{t-1}}\right)=\mathbf{V}_{t-1}\left(\varsigma_{t-1}^{\prime} x_{t}\right)=\varsigma_{t-1}^{\prime} W_{t} \varsigma_{t-1}=\sum_{i=1}^{22} \sum_{k=1}^{22}\left(\varsigma_{t-1}\right)_{i}\left(\varsigma_{t-1}\right)_{k}\left(W_{t}\right)_{i k}
$$

where $y_{t}$ and $\varsigma_{t-1}=\left(\left(\varsigma_{t-1}\right)_{1}, \ldots,\left(\varsigma_{t-1}\right)_{22}\right)^{\prime}$ denote real GDP and the vector of sectoral shares, respectively. The conditional GDP standard deviation is just the square root of this expression. Figure 3 plots this entity for the period 1949-2005. We can see that it decreased more or less gradually from around 3.8 to less than 2 and therefore supports the trend-decline hypothesis expressed by Blanchard and Simon (2001). However, this downward trend speeds up in the early 1950s and the mid-1980s. Because of endpoint issues, the Korean war (e.g., the recovery from the 1949-1950 recession had 13\% growth over four quarters), and the data quality in the early 1950s, we focus our attention on the latter downward acceleration, which corresponds to what is labeled in the literature as the Great Moderation. 


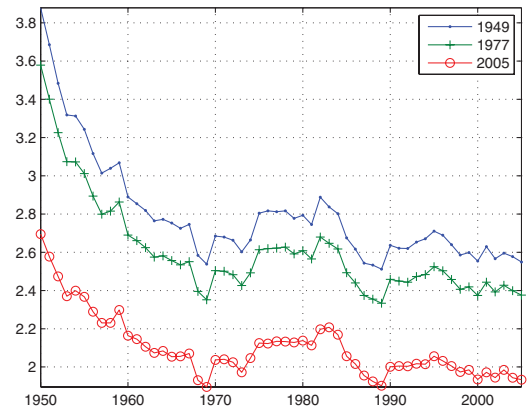

(a) Constant shares

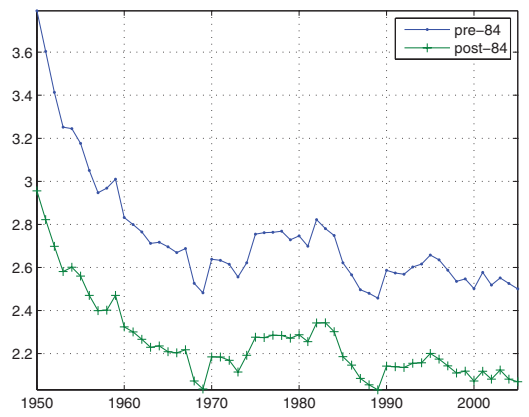

(b) Average shares

FigURE 4. Conditional standard deviation of GDP.

To get an idea of how the composition of output affects its volatility, we compute three counterfactual paths for the conditional GDP standard deviations. These paths are obtained by evaluating equation (6) in each period, fixing the shares at their values in 1949, 1977, and 2005, respectively, but using the same $\left(W_{t}\right)$ sequence. Figure 4a plots these paths. There is an unambiguous ranking: the conditional GDP standard deviation with the 2005 shares is on average $24.7 \%$ (19.1\%) lower over the whole sample than the one with 1949 shares (1977 shares). We get a similar finding if we set the shares to their average pre-1984, respectively post1984 averages, as in Figure 4b. The standard deviation with post-1984 shares is on average $17.7 \%$ lower than pre-1984 values. This suggests that a non-negligible part of the decline in the conditional GDP standard deviation can be attributed to sectoral shifts. The findings are robust if a less persistent WAR(1) is assumed. ${ }^{16}$

\subsection{Unconditional GDP Volatility}

We use simulations to infer the unconditional GDP volatility for given initial (1949) sectoral shares. For this purpose, we use the AR(1) models from Section 2.2 to simulate sectoral production, taking the parameter breaks into account. We draw the innovations from multivariate normals with covariance matrices equal to the filtered $W_{t} \cdot{ }^{17}$ We further compute the standard deviation of the implied GDP growth rate for the pre-1984 and the post-1984 periods. We repeat this exercise 100,000 times and finally compute the average standard deviations that are reported in Table 5 for alternative initial shares. The simulation with the initial shares from 1949 can serve as a check of our specification. In particular, we verify if GDP volatility falls inside the intervals $[2.06,3.24]$, respectively $[1.38,2.62]$, whose bounds correspond to the 5 and $95 \%$ quantiles of the pre-1984, respectively post1984 period. As GDP volatility is 3.21 in the pre-1984, respectively 1.63, in the post-1984 sample, we feel comfortable with our specification.

Table 5 reveals that the average simulated standard deviations depend on the chosen initial sectoral shares. The simulated standard deviation for the 2005 (1977) 
TABLE 5. Average GDP standard deviation

\begin{tabular}{lcc}
\hline Initial shares & $1950-1984$ & $1985-2005$ \\
\hline 1949 & 2.62 & 1.95 \\
1977 & 2.37 & 1.75 \\
2005 & 1.95 & 1.63 \\
\hline
\end{tabular}

initial shares is $25.6 \%(17.7 \%)$ lower in the pre-1984 period than the simulated standard deviation for the 1949 initial shares. For the post-1984 period, the respective percentage is $16.4 \%(10.3 \%) .^{18}$

\subsection{Relevant Sectoral Shifts}

In the previous sections, we have found that GDP volatility depends, to a significant and sizable extents, on its sectoral composition. The purpose of this section is to identify the relevant sectoral changes behind this relationship.

The five most important sectoral shifts-in absolute value and in order of decreasing importance — took place in the sectors durable goods, nondurable goods production, finance and insurance, professional-scientific and technical services, and health care and social assistance. ${ }^{19}$ The numbers in Table 6 show that both durable and nondurable goods production have become less important than the three service sectors finance and insurance, professional-scientific and technical services, and health care and social assistance. In the years 2001-2005, these three service sectors made up over $20 \%$ of real GDP.

Figure 5 plots the filtered standard deviations for these five sectors as computed from $\left(W_{t}\right)$. This chart shows that the two production sectors indeed have higher standard deviations than the three service sectors. This evidence thus confirms our hypothesis that the sectoral shift indeed had a dampening effect on GDP volatility.

A possible drawback of the preceding analysis is that it does not take the evolution of covariance terms into account. We therefore use an alternative method to identify the relevant sectoral shifts. For this purpose we compute the $i k$ th summand in the double sum defining the conditional variance of real GDP growth, $\mathbf{V}_{t-1}\left(\frac{\Delta y_{t}}{y_{t-1}}\right)$, which, according to equation (6), is equal to $\left(\varsigma_{t-1}\right)_{i}\left(\varsigma_{t-1}\right)_{k}\left(W_{t}\right)_{i k}$. This

TABLE 6. Average shares (in percent)

\begin{tabular}{lcc}
\hline Sector & $\begin{array}{c}\text { Average share } \\
\text { 1948-1953 }\end{array}$ & $\begin{array}{c}\text { Average share } \\
\text { 2001-2005 }\end{array}$ \\
\hline Durables & 17.86 & 8.39 \\
Nondurables & 15.04 & 6.14 \\
Finance and Insurance & 3.27 & 9.19 \\
Professional—scientific and technical services & 1.93 & 7.84 \\
Health care and social assistance & 2.02 & 7.83 \\
\hline
\end{tabular}




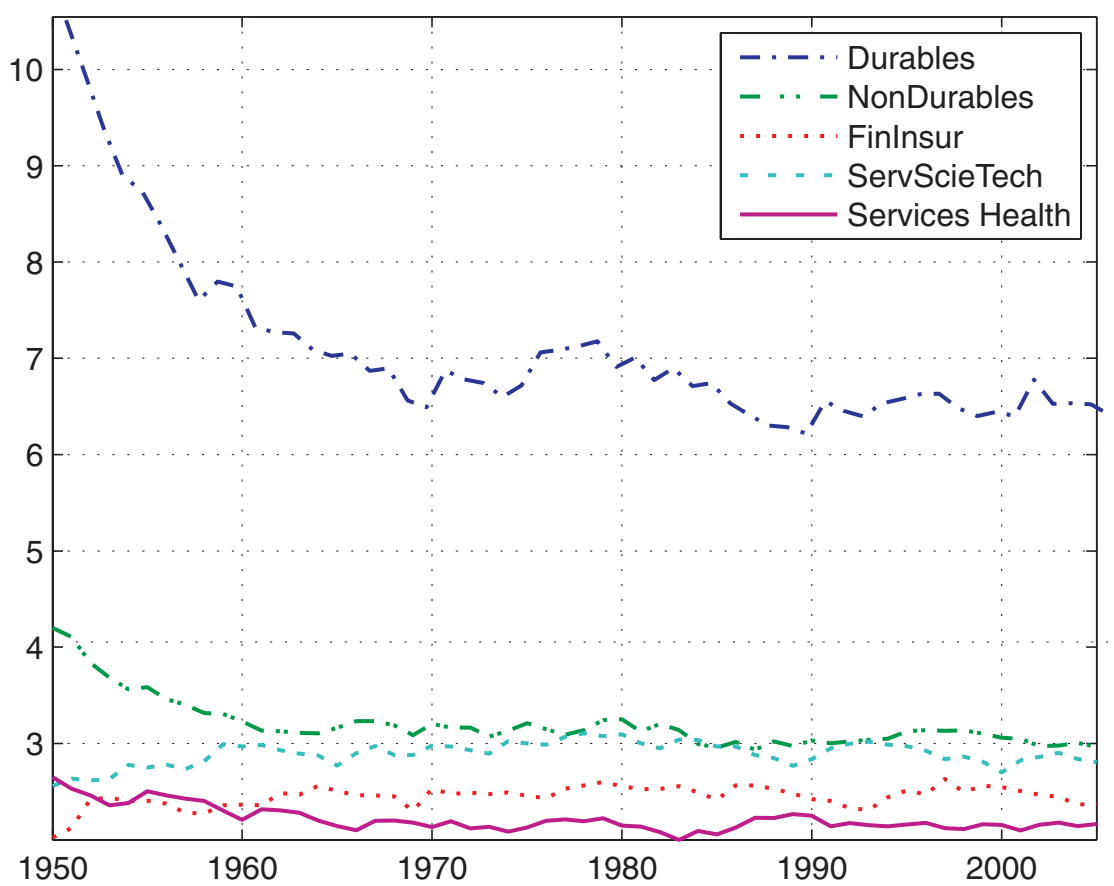

FIGURE 5. Conditional standard deviations of sectors with largest shifts.

analysis takes the path of the entire covariance matrices $\left(W_{t}\right)$ into consideration. It reveals that the variance corresponding to the durable goods sector exhibits the largest decrease. Other significantly decreasing terms correspond, in order of descending magnitude, to

(a) the covariance between durable and nondurable goods production,

(b) the covariance between durable and retail sales,

(c) the covariance between durable goods and wholesale trade, and

(d) the variance of nondurable goods production.

Figure 6 shows a plot of these covariances.

To disentangle the changes in the shifts from the changes in the covariance matrix, we also computed $\varsigma_{t-1}^{i} \varsigma_{t-1}^{k}(\bar{W})_{i k}$, where $\bar{W}$ is the average covariance matrix over the entire sample 1949-2005. We find again that the variance term of durable goods production exhibits the largest decrease. In addition, we find significant decreases for

(a) the covariance term between durable and nondurable goods,

(b) the covariance term between durable goods and retail trade, 


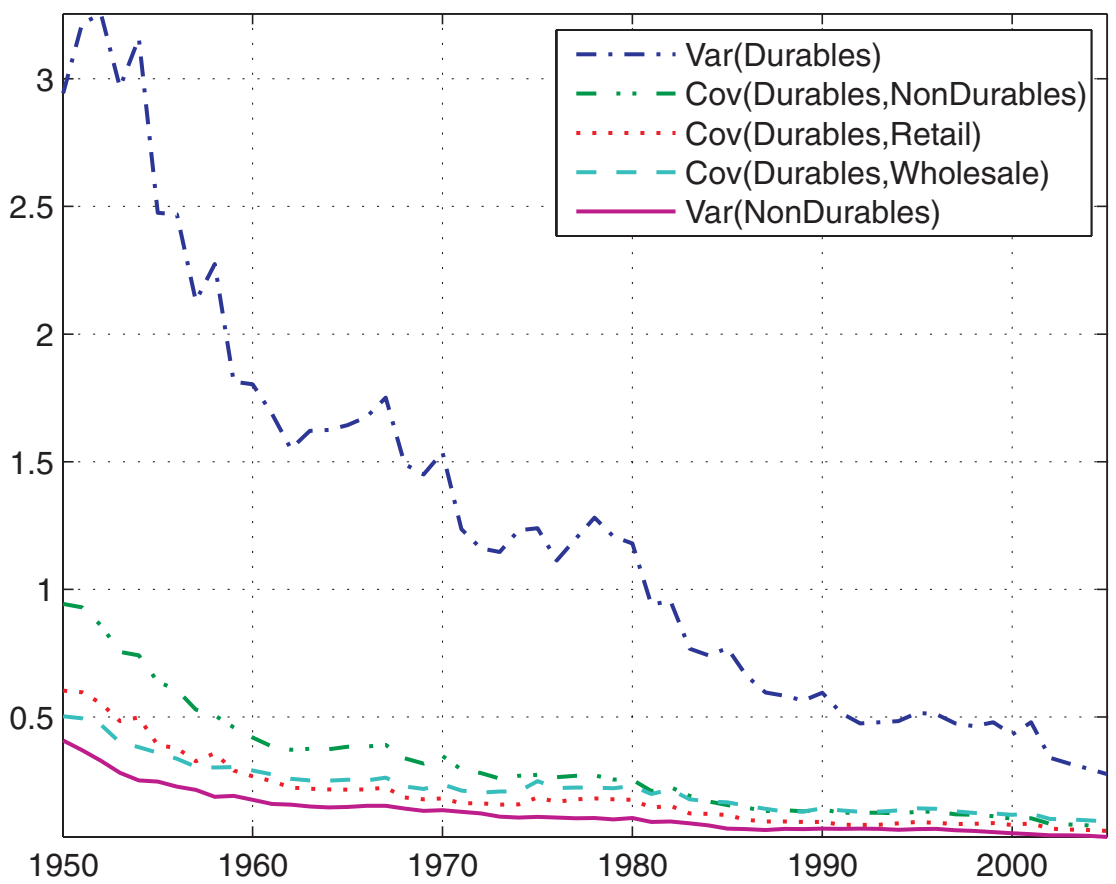

FIGURE 6. Five most important $\varsigma_{t-1}^{i} \varsigma_{t-1}^{k}\left(W_{t}\right)_{i k}$-terms.

(c) the variance term of nondurable goods, and

(d) the covariance term between durable goods and wholesale trade.

These variances and covariances are plotted in Figure 7.

We conclude that the shift out of durable goods production has significantly stabilized real GDP growth. Not only a decrease in the variance term, but also the decrease in covariance terms, let to this stabilization.

\section{CONCLUSION}

We investigated whether and to what extent the decline in the volatility of US GDP, observed for the period 1949 to 2005 , can be attributed to the structural change in its sectoral composition. We found that structural changes alone would account for approximately $30 \%$ of the observed moderation. This evidence was produced from a Wishart autoregressive model that allows for time-varying covariances. Running some counterfactual experiments, we can decompose the effect of structural changes into a pure sectoral change, i.e., changes in the sectoral shares, and a change in sectoral volatility. These experiments indicate that, even if covariance matrices are held constant, pure sectoral changes explain $15 \%$ of the decline in GDP volatility. In addition, the conditional standard deviation of GDP growth would have been, on average, 24.7\% lower if sectoral shares in 1949 had been 


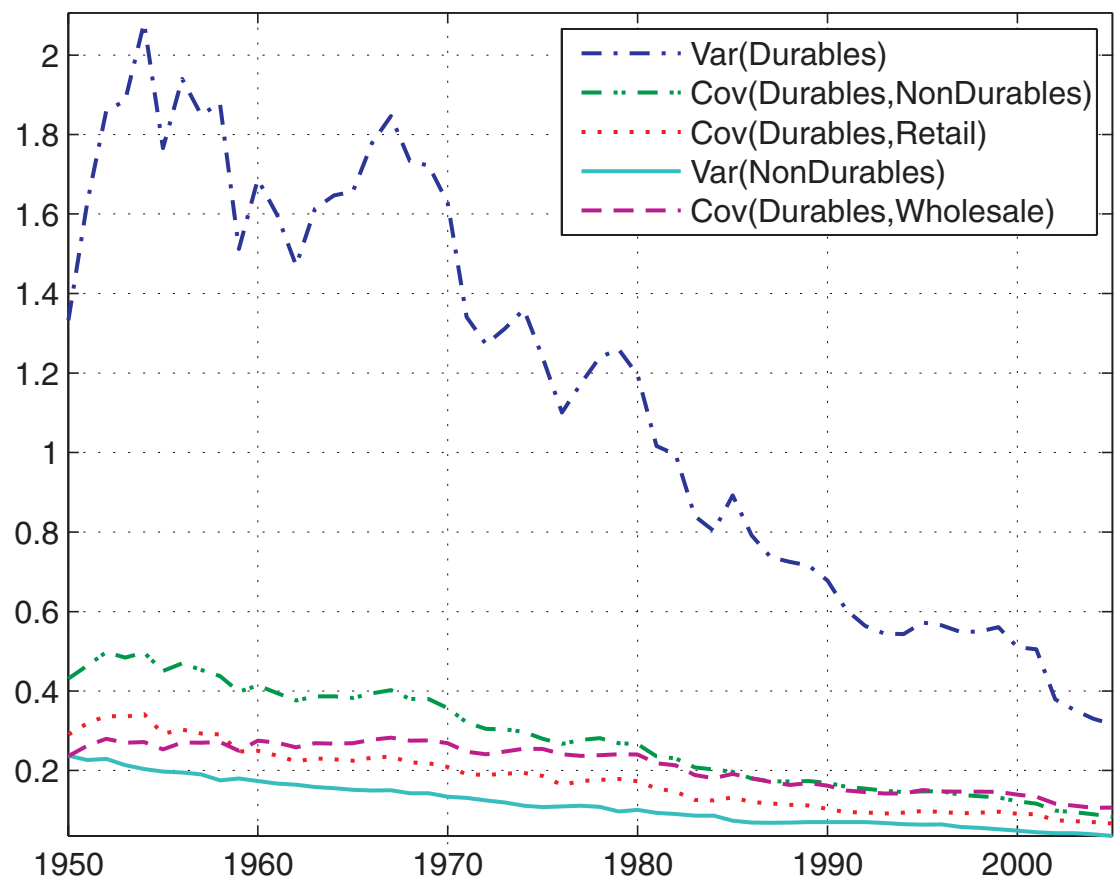

FIGURE 7. Five most important $\varsigma_{t-1}^{i} \varsigma_{t-1}^{k}(\bar{W})_{i k}$-terms.

equal to those in 2005. For the unconditional standard deviation, the reduction would have been $25.6 \%$.

This evidence is driven to an important extent by the reduction in the share of durable goods production. This result is well in line with those of McConnell and Perez-Quiros (2000), who argue that the reduction in the variance of durable goods production alone can account for the break in GDP volatility. Furthermore, the increased openness of the U.S. economy is consistent with this reasoning, as it made it possible to outsource production, in particular durable goods production, to other countries. ${ }^{20}$ However, the cumulative sums-of-squares test of Inclán and Tiao (1994) showed that durable goods production is the only sector with a significant reduction in its conditional variance. Some sectors, such as mining, utilities, and information, even experienced an increase. These findings cast some doubt on the Good Luck hypothesis.

Many of the existing economic models, which focus on business cycles, shut out the growth component. However, as we have shown, this leaves out an important part of the story. Therefore, future research should aim at developing behavioral models that rationalize the observed sectoral shifts and link economic growth and volatility. Promising sources of inspiration could be Bernanke (1983) and Pindyck (1991). They argue that the option character makes irreversible investment decisions prone to risk. Increased uncertainty pushes the investor to postpone projects 
and wait for new information about prices, costs, and other market conditions. This leads to a negative relationship between growth and volatility. Similar arguments can be put forward in the case of human capital accumulation [see Martin and Rogers (1987) or Blackburn and Galindev (2003)].

\section{NOTES}

1. Kim and Nelson (1999) and McConnell and Perez-Quiros (2000) provide the first published expositions of this fact.

2. For further properties and a deeper discussion we refer to the original article by Gourieroux et al. (2009). This paper also provides additional justifications for this approach, in particular with regard to multivariate GARCH models.

3. The implicit GDP deflator is from the BEA and is given by the ratio of the GDP is current-dollar value to its chained-dollar value.

4. Agriculture had negative average growth. We took its absolute value.

5. Except for the sectors agriculture, health care and social assistance, and federal government, the $\mathrm{AR}(1)$ structure is sufficient to characterize the data. Evidence on this point can be obtained from the authors.

6. The ICSS test also indicates significant volatility breaks for agriculture (the one period-forecast standard deviation increased from 5.90 to 13.75 in 1972) and federal government (the conditional standard deviation decreased from 14.70 to 2.13 in 1953). However, significant autocorrelation in the residuals violates the assumptions of the ICSS test. Thus the results for these two sectors are not reliable.

7. It also indicates a significant decrease in federal government variance; however, this could be spurious, because there is significant correlation left in these residuals.

8. $\|\cdot\|$ denotes the operator norm. The submultiplicative property of the operator norm implies that the condition is satisfied if the product of the two largest eigenvalues is less than 0.5 .

9. Engle and Kroner (1993) and Tse and Tsui (2002) discuss MGARCH models.

10. The operator vech(.) stacks the different elements in $\Sigma$; because there are

$$
n_{e}:=\frac{n_{s}\left(n_{s}+1\right)}{2}
$$

such different elements, there are $n_{e}$ equations each involving $n_{e}$ regressors, which gives the $n_{e}^{2}$ parameters in $A$.

11. See Gourieroux et al. (2009).

12. These methods have been used in economics by An (2005) and by Fernandez-Villaverde and Rubio-Ramirez (2007) to estimate a second-order approximation to dynamic stochastic general equilibrium models (DSGE models).

13. Other values of $\lambda$ lead to the same conclusions regarding the contribution of sectoral shares in GDP volatility. A higher $\lambda$ means that the Wishart is more persistent and has weaker innovations.

14. Agriculture, federal government, and state and local government are left out.

15. Graphs of filtered standard deviations of other series, as well as graphs of filtered covariances, are available from the author upon request.

16. Further counterfactual calibrations are available from the authors upon request.

17. Because the AR(1) parameters are different, sectors grow at different rates in our simulations, and therefore, shares depart from their initial values. We did not choose to calibrate AR(1) parameters such that shares would stay, on average, close to their initial values. The reason is that there are many different possible calibrations that can do this and that have, by themselves, different implications on simulated GDP volatility.

18. The results do barely change with different Wishart calibrations. 
19. The absolute difference of the average shares in the years 1948-1952 and the average shares in the years 2001-2005 is computed. The list hardly changes if, instead, the absolute difference between pre-1984 and post-1984 average shares is taken.

20. See Barrell and Gottschalk (2004), who relate the increased openness to the decline in U.S. output volatility.

\section{REFERENCES}

Sungbae, An (2005) Bayesian Estimation of DSGE Models: Lessons from Second-Order Approximations. Mimeo.

Andrews, Donald W.K. and Werner Ploberger (1994) Optimal tests when a nuisance parameter is present only under the alternative. Econometrica 62, 1383-1414.

Arulampalam, M. Sanjeww M., Simon Maskell and Neil Gordon and Tim Clapp (2002) A tutorial on particle filters for online nonlinear/non-Gaussian Bayesian tracking. IEEE Transactions on Signal Processing 50, 174-188.

Ray Barrell and Sylvia Gottschalk (2004) The volatility of the output gap in the G7. National Institute Economic Review 188, 100-107.

Ben S. Bernanke (1983) Irreversibility, uncertainty and cyclical investment. Quarterly Journal of Economics 98, 85-106.

Blackburn, Keith and Ragchaasuren Galindev (2003) Growth, volatility and learning. Economics Letters 79, 417-421.

Blanchard, Olivier and John Simon (2001) The long and large decline in U.S. output volatility. Brookings Papers on Economic Activity 2001(1), 135-166.

Engle, Robert F. and Kenneth F. Kroner (1993) Multivariate simultaneous generalized ARCH. Econometric Theory 11(1), 122-150.

Fang, Wen-Shwo and Stephen M. Miller (2008) The Great Moderation and the relationship between output growth and its volatility. Southern Economic Journal 74(3), 819-838.

Fernandez-Villaverde, Jesus and Juan F. Rubio-Ramirez (2007) Estimating macroeconomic models: A likelihood approach. Review of Economic Studies 74, 1059-1087.

Galí, Jordi and Luca Gambetti (2009) On the sources of the Great Moderation. American Economic Journal: Macroeconomics 1(1), 26-57.

Gourieroux, Christian, Joann Jasiak and Razvan Sufana (2009) The Wishart autoregressive process of multivariate stochastic volatility. Journal of Econometrics 150(2), 167-181.

Inclán, Carla and George C. Tiao (1994) Use of cumulative sums of squares for retrospective detection of changes of variance. Journal of the American Statistical Association 89, 913-923.

Kim, Chang-Jin and Charles R. Nelson (1999) State-Space Models with Regime Switching. Cambridge, MA: MIT Press.

Martin, Philppe and Carol Ann Rogers (1987) Long-term growth and short-term economic instability. European Economic Review 49, 359-381.

McConnell, Margret M. and Gabriel Perez-Quiros (2000) Output fluctuations in the United States: What has changed since the early 1980's? American Economic Review 90, 1464-1476.

Neusser, Klaus (2008) Interdependencies of US manufacturing sectoral TFPs: A spatial VAR approach. Journal of Macroeconomics 30, 991-1004.

Pindyck, Robert S. (1991) Irreversibility, uncertainty and investment. Journal of Economic Literature $29,1110-1148$.

Primiceri, Giorgio E. (2005) Time varying structural vector autoregressions and monetary policy. Review of Economic Studies 72, 821-852.

Stock, James H. and Mark W. Watson (2005a) Implications of dynamic factor models for VAR analysis. Mimeo.

Stock, James H. and Mark W. Watson (2005b) Understanding changes in international business cycle dynamics. Journal of the European Economic Association 5, 968-1006. 
Tse, Y.K. and Albert K.C. Tsui (2002) A multivariate generalized autoregressive conditional heteroskedasticity model with time-varying correlations. Journal of Business and Economic Statistics 20(3), 351-362.

\section{APPENDIX A: FILTERED COVARIANCES OF DURABLES}
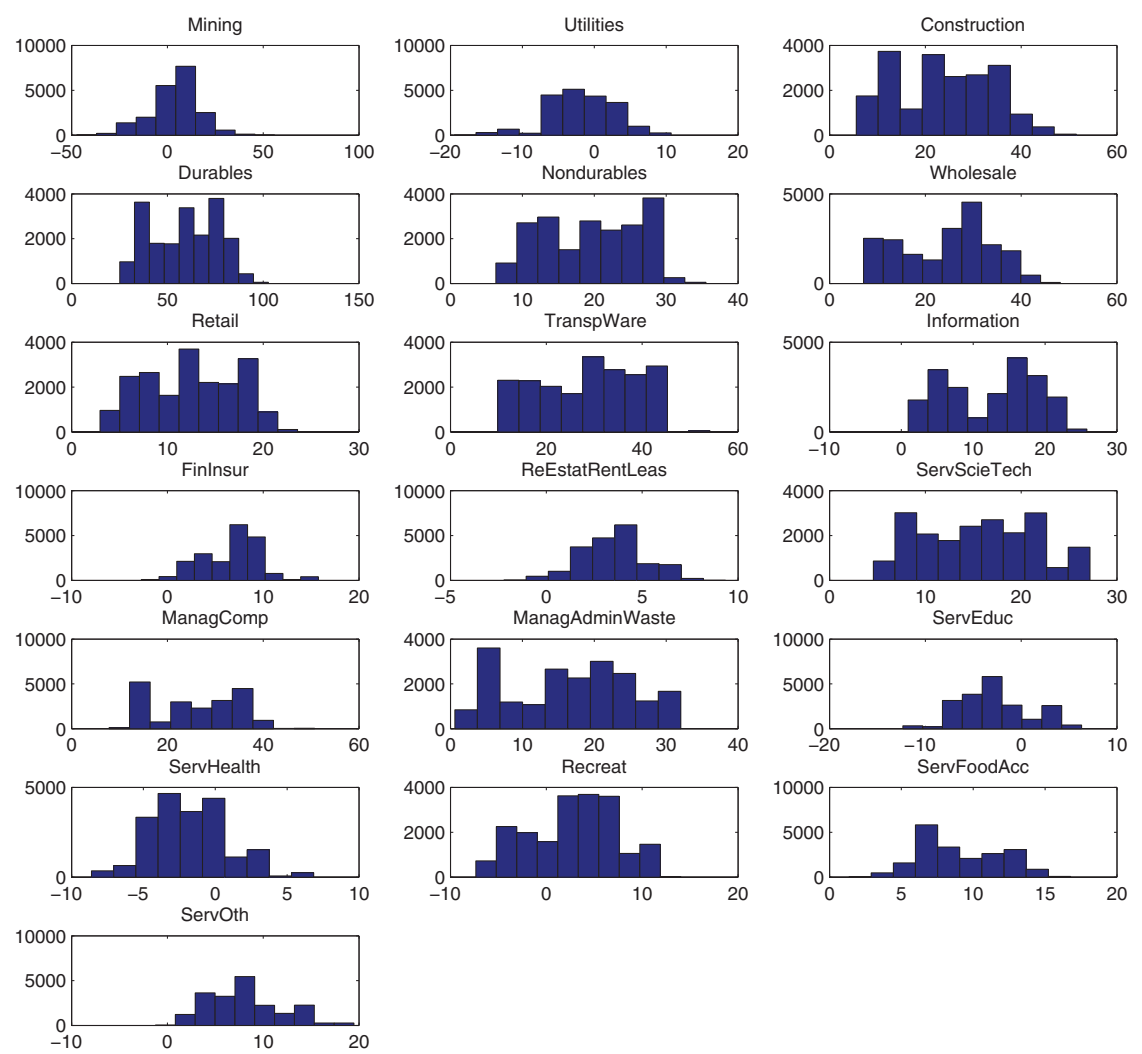

FIGURE A.1. Filtered covariances between durables and other sectors. 


\section{APPENDIX B: FILTERED STANDARD DEVIATIONS}
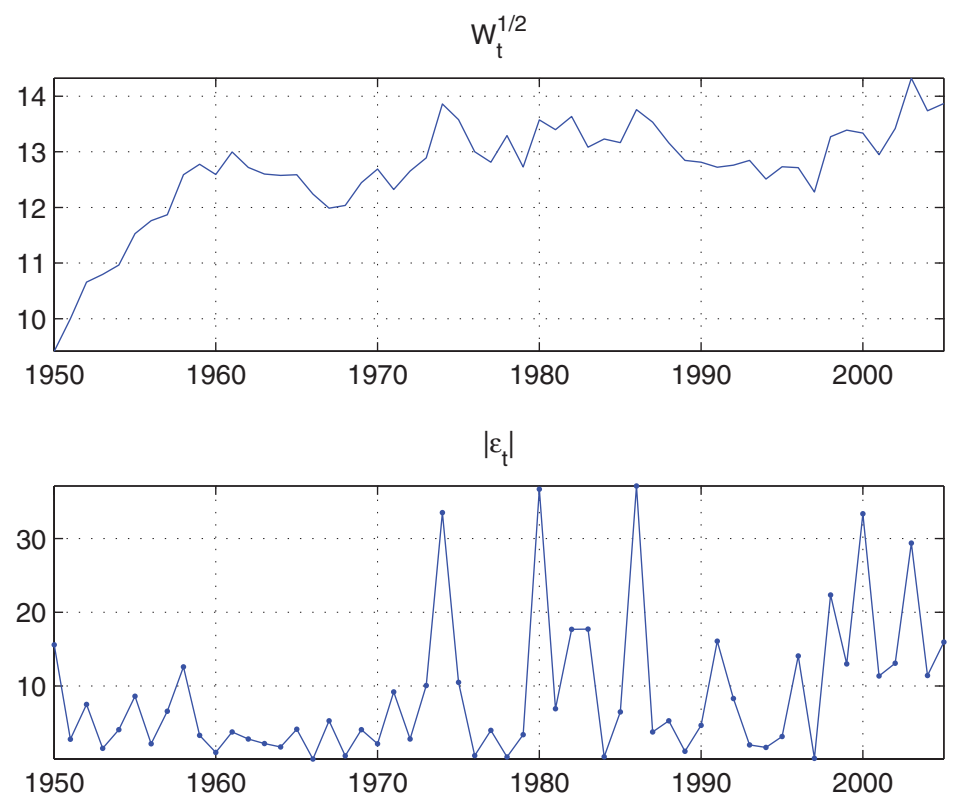

FIGURE B.1. Filtered standard deviations for the mining sector.

In order to save space, only the filtered standard deviations for mining, utilities, durable goods, and information are reported (Figures B.1-B.4). All other graphs are available upon request. For these four sectors, the ICSS test detected breaks in the conditional variance (see Table 3). The upper graph shows the filtered standard deviations. The bottom graph plots the absolute values of the residuals from the AR(1) regressions. 


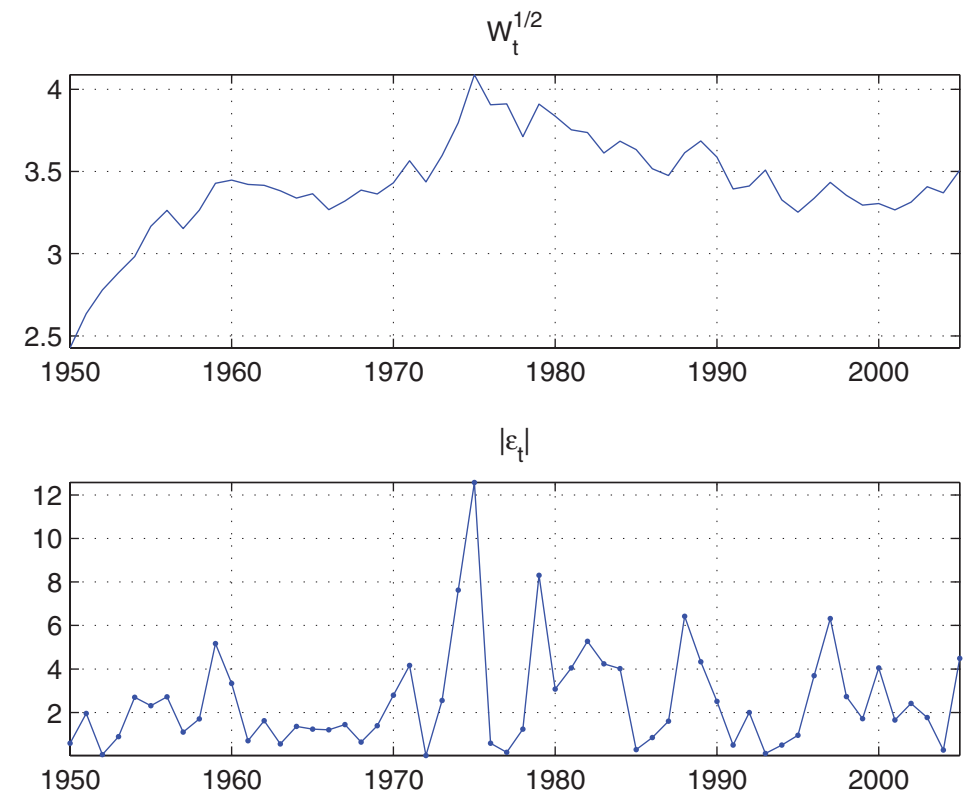

FIGURE B.2. Filtered standard deviations for the utilities sector.

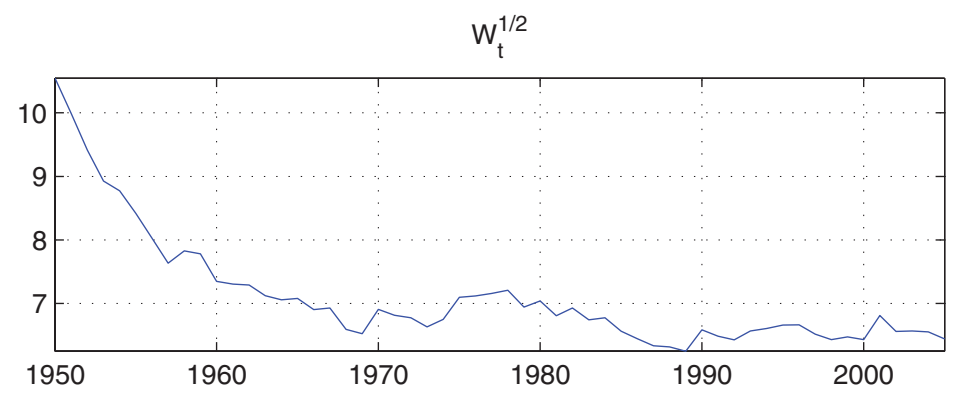

$\left|\varepsilon_{t}\right|$

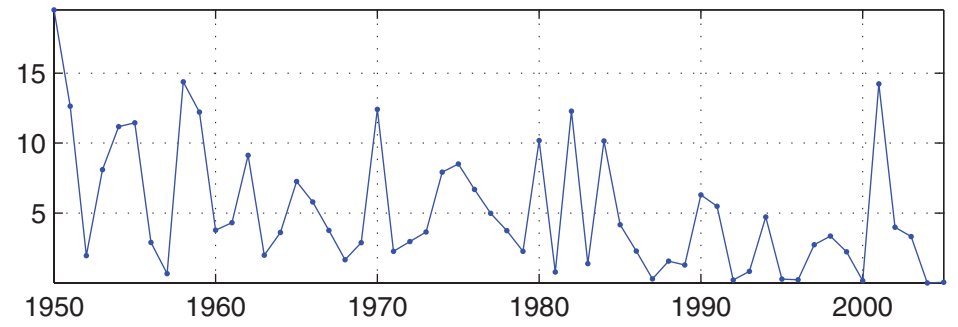

FIGURE B.3. Filtered standard deviations for the durables sectors. 

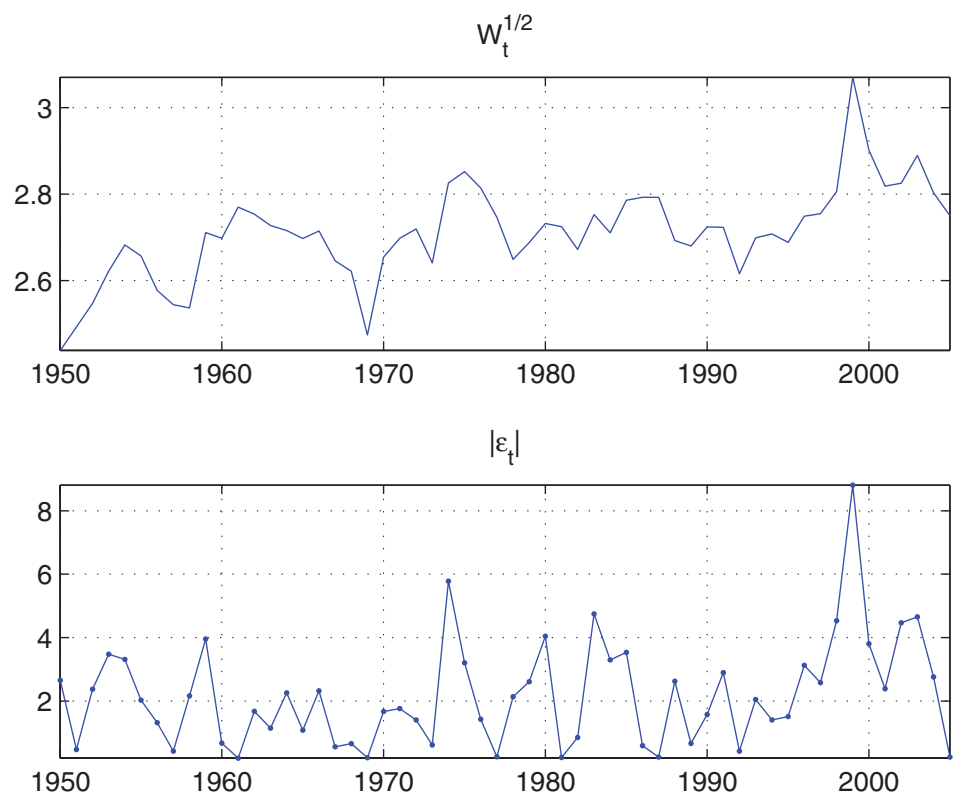

FIGURE B.4. Filtered standard deviations for the information sector. 